\title{
Inmigrantes tempranos: maragatos en la Patagonia argentina. Las cuevas del Fuerte Nuestra Señora de El Carmen
}

\author{
María Laura CASANUEVA \\ Universidad de Buenos Aires - Instituto Nacional de Antropología y Pensamiento Latinoamericano \\ mlauracasanueva@gmail.com
}

Recibido: 28 de julio de 2010

Aceptado: 22 de junio de 2011

\section{RESUMEN}

El pequeño grupo de maragatos que arribó junto a las demás familias españolas al Fuerte y Población Nuestra Señora de El Carmen (hoy ciudad de Carmen de Patagones), como parte de la original iniciativa borbónica: el «Plan Patagónico de 1778», llegó a identificar con su nombre tanto a todos los nacidos en esta ciudad, como a las cuevas en las que debieron cobijarse al momento de su arribo. El objetivo de nuestra investigación es acceder a la vida cotidiana en estos primigenios espacios domésticos, para ello proponemos aplicar las herramientas teórico-metodológicas que nos ofrecen la Historia, la Arqueología y la Antropología; este enfoque nos está permitiendo armar el rompecabezas social de las primeras décadas de existencia de un paraje emblemático de la Patagonia.

Palabras clave: Plan Patagónico, Fuerte Nuestra Señora de El Carmen, maragatos, cuevas, Arqueología/ Antropología.

\section{Early Immigrants: Maragatos in Patagonia, Argentina. The Caves of Fort of Nuestra Señora de El Carmen}

\begin{abstract}
The small group of Maragatos (people from Maragatería), that arrived together with the rest of the Spanish families at Nuestra Señora de El Carmen fort and village (today known as the city of Carmen de Patagones) as part of the Patagonian plan called «Plan Patagónico de 1778», identified with its name all the people born in this city and the caves where they had to shelter when they first arrived. Through this research, we aim at getting to know what everyday life was like in these original domestic spaces. To that end, we propose applying the theoretical and methodological tools provided by History, Archeology and Anthropology. This approach is enabling us to reconstruct the social puzzle of the first decades of existence of this symbolic place of Patagonia.
\end{abstract}

Key words: Patagonian Plan, Fort Nuestra Señora de El Carmen, Maragatos, caves, Archeology/Anthropology.

Sumario: 1. Introducción. 2. Fuentes utilizadas. 3. La inmigración temprana en el Río de La Plata. 4. Los maragatos: arrieros y aventureros. 5. Panorama histórico. 6. La inmigración española hacia El Carmen. 7. La sociedad de El Carmen durante las primeras décadas. 8. Las cuevas de la costa del río Negro. 9. Rastreando tradiciones maragatas. 10. Búsqueda material de la presencia maragata. 11. ¿Por qué maragatos? 12. Palabras finales. 13. Referencias bibliográficas.

\section{Introducción}

La tradición argentina de país receptor de inmigrantes, principalmente europeos, se puede rastrear desde el Virreinato del Río de la Plata cuando Buenos Aires era entrada y salida del cono sur americano. A finales del siglo XVIII un grupo de familias españolas arribaron a las costas platenses con la esperanza de una vida económicamente 
mejor y más estable; estas personas provenían del norte de España, mayoritariamente de Asturias, Galicia y Castilla y León, la particularidad de esta inmigración fue la llegada de un grupo de maragatos en los distintos contingentes trasatlánticos.

Estas familias de labradores, artesanos y pequeños comerciantes, fueron los protagonistas del renombrado «Plan Patagónico de $1778 »{ }^{1}$, originando la gesta patagónica que sintetizó la innovadora política borbónica para con las colonias americanas e instauró un sistema para poblar los confines más australes del continente: la contrata de familias. Proyecto de una envergadura única hasta el momento, que implicó la fundación de los fuertes de Floridablanca, San José y Nuestra Señora de El Carmen y que pasó a la historia como un estrepitoso fracaso; sin embargo, las actuales investigaciones arqueológicas e históricas en Floridablanca y San José, matizan la idea de fracaso (Bianchi 2007; Senatore 2007).

Más allá de las citadas colonias de la costa patagónica, que a poco de ser fundadas debieron ser abandonadas de inmediato, el éxito, la perdurabilidad y la trascendencia histórica de una de ellas: «Nuestra Señora de El Carmen» (hoy ciudad de Carmen de Patagones $^{2}$ ), erigida sobre la costa norte del río Negro (Figura 1), demuestra que aquel plan del período tardo colonial no fue un error sino una estrategia; la misma, no sólo materializó la intención Real de protección de las colonias, sino que representó un hito en la historia argentina.

El caso de estudio aquí presentado tiene la particularidad de sintetizar dos grandes sucesos, por un lado la supervivencia y éxito de Nuestra Señora de El Carmen como enclave históricamente emblemático, y por otro lado, la existencia y conservación de las primeras moradas labradas en la barranca rionegrina por los inmigrantes españoles, lo que dio origen a una serie de cuevas-hogar, hoy conocidas popularmente como «cuevas maragatas». Estas estructuras domésticas, que si bien no son exclusivas de Patagones, se destacan, en primera instancia, por su gran escala cuantitativa y distributiva a lo largo de todo el paisaje costero y asimismo sobresalen por su utilización continua desde el momento de la fundación hasta el presente.

1 El Plan de población puesto en marcha a partir de 1778, era insólito para la época; este plan formaba parte de una estrategia general cuyo objetivo era poner en marcha la gran máquina comercial -relacionado con la aplicación del reglamento del libre comercio-. Los hombres más representativos de esta empresa fueron D. José de Gálvez (antiguo visitador de Nueva España y Marqués de Sonora) que desempeñaba el cargo de Secretario General del Despacho de Indias; D. Jorge Astraudi, comisario intendente encargado de la colectación de familias de labradores convocadas; y en el Río de la Plata, el Virrey Juan José de Vértiz, y por encima de ellos se cernía la figura de D. José Moñino, Conde de Floridablanca. El sistema fue la contrata, que consistió en un documento por el cual se fijaron las condiciones que la Corona otorgaría a los que acudieran al llamado para ir al Río de la Plata y la obligación a la que se sujetaban los pobladores. El sistema empleado resultó ser diferente del tipo de reclutamiento preponderante en el siglo XVI, este nuevo procedimiento representaba la adscripción a la tierra como sistema poblacional, inspirado en el ejemplo de Sierra Morena que, a fines de 1776, parecía constituir un notable éxito (Porro 2005).

2 El actual partido de Patagones es el punto más austral de la provincia de Buenos Aires y se considera el más extenso de los distritos bonaerenses, se ubica en el extremo meridional de la provincia a $40^{\circ} 49^{\prime}$ de Lat. Sur y $63^{\circ} 00^{\prime}$ de Long. Oeste, siendo sus límites los siguientes: al Norte el partido de Villarino, al Este y Sudeste el Océano Atlántico, al Sudoeste el Río Negro y al Oeste las provincias de Río Negro y La Pampa. Por esta situación biogeográfica particular y transicional entre las regiones pampeana y patagónica podría denominárselo como la «antesala de la Patagonia» (Bandieri 2005). La ciudad cabecera, Carmen de Patagones, está situada en el extremo sur del partido a orillas del Río Negro (Levene 1941). 


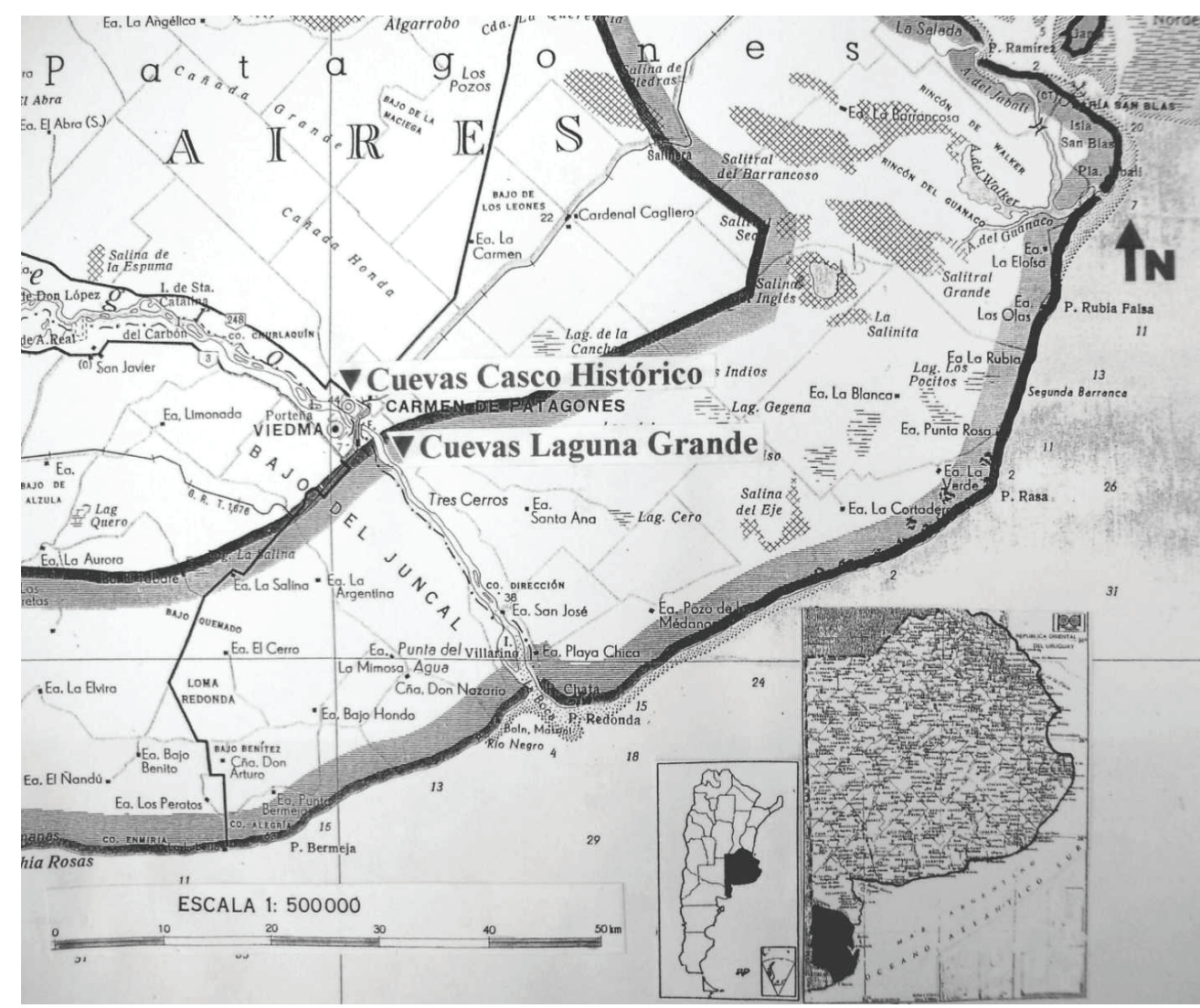

Figura 1: Ubicación de Carmen de Patagones y cuevas maragatas en la Provincia de Buenos Aires.

Este artículo consiste en caracterizar la inmigración que fundó Carmen de Patagones y estudiar el registro arqueológico asociado a ella. Aunque esta inmigración ya ha sido estudiada con anterioridad (Biedma 1887; Apolant 1970; Ramos 1982; Zusman 1999; Jaime 2001; Porro 2005; Devoto 2004; De Cristóforis 2006; entre otros), la novedad de nuestra propuesta radica en el hecho de abordar su investigación integrando las estructuras habitacionales en las que vivieron los primeros pobladores. Esta propuesta que indaga en el pasado de una fundación española en territorio indígena, intenta acercar información sobre un tema de actualidad como es el encuentro entre dos culturas totalmente distintas y las estrategias planteadas para lograr su supervivencia.

El objetivo general del proyecto, es acceder al conocimiento de los procesos históricos de establecimiento, continuidad y cambio, en poblaciones de origen europeocriollas y su vinculación con poblaciones indígenas, durante los siglos XVIII y XIX en la región de Pampa-Patagonia. Hacemos hincapié, entonces, en los distintos grupos sociales que se asentaron en la Patagonia Septentrional, desde distintas regiones de España, especialmente de la zona de Castilla y León y de ella las familias provenientes de la Maragatería (pequeña región ubicada al Noroeste de León). 
El propósito último es conocer y revalorizar los espacios domésticos relacionados con la vida cotidiana de los primeros colonos españoles e indagar en la memoria popular acerca del origen de las «cuevas-hogar», explorando las bases reales o imaginarias de la identificación de la población actual con la población maragata de aquel entonces ${ }^{3}$.

\section{Fuentes utilizadas}

Para esta investigación se tuvo en cuenta bibliografía editada relacionada con el momento histórico que nos ocupa, el suceso propio de la fundación y las características de la sociedad maragata. En cuanto a las fuentes documentales de primera mano, nos centramos en los Libros Parroquiales de Carmen (Matrimonios, Bautismos y Defunciones) desde el período de la fundación hasta mediados del siglo XIX; también nos valimos de los escritos e investigaciones de la ex Directora del Museo Histórico de Patagones, Sra. Emma Nozzi, acerca de las cuevas y el primer momento de ocupación de la ciudad, documentos hoy atesorados en su Archivo Histórico. Asimismo nos servimos de los inventarios de este mismo museo (Museo Histórico Regional Emma Nozzi), así como de la colección de piezas de origen maragato del Museo del Traje de Madrid.

A su vez, los relatos recopilados y las entrevistas efectuadas a personas allegadas a la historia de Carmen, así como a descendientes y maragatos genuinos, fueron una fuente de datos de suma importancia.

Por último, la arqueología aportó la distintiva visión de la cultura material producto del momento de llegada, fundación del enclave en estudio y supervivencia en él (las estructuras de habitación en sí mismas y el material arqueológico hallado en ellas, relacionado con las actividades cotidianas de sus ocupantes).

Todas las fuentes consultadas orientaron el buen camino de nuestra búsqueda y nos han brindado un panorama completo y complejo del tema en discusión.

\section{La inmigración temprana en el Río de La Plata}

Argentina ha sido históricamente un país receptor de población, principalmente del continente europeo, este movimiento humano ha sido facilitado por distintas circunstancias: favorables políticas jurídicas migratorias (Devoto 2004), variedad de recursos naturales, un benéfico clima templado, y fundamentalmente, determinadas condiciones socio-económicas que brindaron un mercado de trabajo en expansión, disponibilidad de territorios para su ocupación y explotación y redes sociales que favorecieron la llegada de nuevos inmigrantes; éstas y otras situaciones propicias, facultaron principalmente la instalación de campesinos y labradores.

\footnotetext{
3 Las instituciones que apoyan, avalan y financian este Proyecto son: la Universidad de Buenos Aires (a través del Proyecto UBACyT F131 - Facultad de Filosofía y Letras), el Instituto Nacional de Antropología y Pensamiento Latinoamericano (INAPL), el Museo Histórico Regional Emma Nozzi (como representante de la Municipalidad de Patagones) y la Dirección de Patrimonio Histórico de Patagones. La investigación se enmarca, además, en un Convenio realizado entre la Universidad de Buenos Aires (U.B.A. Facultad de Filosofía y Letras) y la Municipalidad de Patagones a través del Museo Histórico Regional Emma Nozzi de Carmen de Patagones; y forma parte del Proyecto de Doctorado de la autora, dirigido por la Dra. Cecilia Pérez de Micou.
} 
Fernando Devoto (2004), resalta tres épocas migratorias: las migraciones tempranas (período tardo colonial), las de masas (De 1870 hasta 1930) y las contemporáneas (siglo XX). Aquí nos centraremos en la primera de ellas.

La noción de inmigrante es bastante elusiva y fue cambiando a lo largo del tiempo. Los términos extranjero, viajero, inmigrante, exiliado, pasajero, fueron los más comunes para definir a distintos tipos de personas que llegaron a la Argentina desde el exterior. Es aún más complicado hablar de inmigrante antes del período de inmigración masiva (De 1870 hasta 1930) en el que predomina la imagen de inmigrantetrabajador europeo; pero ¿los numerosos europeos que llegaron en la época colonial deberían ser considerados inmigrantes? Actualmente sí se los considera dentro de este segmento, exceptuando a esclavos y funcionarios españoles llegados a Indias: civiles o militares, laicos o eclesiásticos (Devoto 2004: 23-24). El resto de los llegados a América para entonces se encuentran dentro de la categoría de inmigrante y se distinguen por poseer ciertas características comunes: en primera instancia el hecho de haberse trasladado desde sus tierras de origen, ya sea como consecuencia de razones individuales o mecanismos migratorios impulsores, así como deseos mancomunados de «mejor fortuna», «espíritu de aventura» o «miseria» (Devoto 2004: 24).

Con estas definiciones nos adentramos en nuestra problemática radicada en el período tardo colonial, momento en el cual se da un viraje en los puntos expulsores de personas, del acento puesto en el sur de España (el puerto de Cádiz en primera instancia), se incorporan los puertos del norte de la península Ibérica. Se ha señalado que en el siglo XVIII se produce una septentrionalización del conjunto del flujo desde España, lo que implica un rol preponderante de todo el arco atlántico, de Vizcaya a Galicia (Carlos Martínez Shaw citado en Devoto 2004: 203).

La oleada de españoles hacia el Río de la Plata presentó dos grupos bien diferenciados que, en cierto modo, reflejaron la superposición de dos fases; a la más antigua de funcionarios y comerciantes se le agregaba ahora otra de simples personas a la búsqueda de trabajo, estos eran tanto pequeños comerciantes como trabajadores de jornada. A ellos se agregaban las personas de procedencia rural llegados en programas de poblamiento, de los que el más conocido para el Río de la Plata fue el de la Operación Patagonia de 1778 a 1784 (Apolant 1970; Devoto 2004; De Cristóforis 2006). Las migraciones del Siglo XVIII, a su modo iniciales de nuevos movimientos migratorios no necesariamente ligados con los de las centurias precedentes (y con otras características laborales), proceden de áreas cercanas al mar por razones vinculadas con las vías de difusión de información (cerca de los puertos) y luego penetran hacia el interior (Devoto 2004: 203; De Cristóforis 2006). Es este caso el que desarrollaremos aquí, la inmigración desde el norte de España y especialmente desde la Maragatería a partir de un momento tan temprano como las últimas décadas del período colonial.

\section{Los maragatos: arrieros y aventureros}

Pero ¿quiénes eran los maragatos?, ¿fue la causa de su traslado a América la misma que trajo a sus coetáneos?, ¿cómo llegaron a identificar a los pobladores de El Carmen?

Los maragatos provienen de la Maragatería, región que se localiza al noroeste de la provincia de León, al suroeste de Astorga y al abrigo de las sierras del Teleno, Man- 
zanal y Foncebadón, ocupando una extensión de $400 \mathrm{~km}^{2}$. Hoy alberga a cuarenta y cuatro pueblos distribuidos en ocho ayuntamientos: Brazuelo, Castrillo de los Polvazares, Lucillo, Luyego, Rabanal del Camino, Santa Colomba de Somoza, Santiago Millas y Val de San Lorenzo; su capital es Astorga.

La Maragatería recibe este nombre desde que los hombres dedicados a la arriería, en torno al siglo XVI, son denominados maragatos. Desde el punto de vista etimológico la denominación maragato parece tener su procedencia de mericator o mercator nacida del oficio de mercaderes que tanto desarrollaron los maragatos. Aunque aún existen encontradas opiniones acerca del origen de esta denominación (ver Rubio 2003).

La situación geográfica de estas tierras, punto intermedio y paso obligado de comunicación entre la meseta castellana y las provincias de Galicia y Asturias, favoreció el negocio de transporte de todo tipo de mercaderías a lomo de mulo. Esta actividad tomó especial relevancia desde el siglo XVI hasta el XIX y es la que dará, a este grupo social, la clave del éxito y una actitud social diferente del resto de la sociedad campesina.

Llegará la época dorada para la arriería maragata durante la primera mitad del siglo XVIII, cuando se lograron las grandes fortunas, fundaron mayorazgos y formaron sus propias reglas socio-culturales. Esta situación social particular se verá reflejada en un tipo de arquitectura popular de viviendas espaciosas, cuya vida discurre en torno a un gran patio interior con muy pocas aberturas al exterior, constituyendo un fiel reflejo de esa vida interior del hombre maragato (Rubio 1995, 2003). Al finalizar este siglo una fuerte crisis agraria provocó un excesivo aumento de los precios de las mercaderías, una caída del consumo y una recesión en los intercambios. Ante tal situación se detectó un claro empobrecimiento de la comunidad arriera maragata, esto afectó en mayor medida a los grupos más débiles que debieron emigrar hacia los centros urbanos o hacia América, animados por el incremento comercial en estas colonias (Rubio 2003).

Seguramente este debilitamiento económico, así como la notoria austeridad de sus tierras originarias -que impidió la reconversión a una economía agrícola-ganadera(Bustos 1989; Rubio 2003), impulsaron a un grupo de maragatos a aventurarse hacia alta mar para poblar los territorios patagónicos a fines del siglo XVIII, dando origen así a esta historia de poblamiento de la costa rionegrina.

\section{Panorama histórico}

La información obtenida ${ }^{4}$ nos permite decir que hacia fines del siglo XVIII las posesiones de España en el Atlántico Sur se veían desprotegidas. Como intento para revertir esta situación la política de los Borbones intenta afianzar el poder en estos territorios, amenazados por la constante presencia extranjera. En este contexto pue-

${ }^{4}$ La investigación en archivo hasta el presente (consultando bibliografía editada y algunos manuscritos de primera mano) se centró en: el Archivo Histórico del Museo Histórico Regional Emma Nozzi de Carmen de Patagones; Asociación Española y Biblioteca Popular Cervantes (Carmen de Patagones); Biblioteca Histórica Provincial de Río Negro (Viedma); Museo Antropológico Histórico «Gdor. Eugenio Tello» (Viedma); Archivo General de la Nación; Videoteca y Biblioteca «Juan Alfonso Carrizo» del INAPL; Instituto de Historia Argentina y Americana «Dr. Emilio Ravignani»; Instituto de Historia de España «Claudio Sánchez Albornoz»; Biblioteca Central «Prof. Augusto Raúl Cortazar» de la Facultad de Filosofía y Letras, entre otros. 
den destacarse tres objetivos de esta política: realizar una exploración que permitiese conocer tanto el ámbito natural como a sus habitantes, buscar nuevas rutas que posibilitaran la comunicación con Chile fortaleciendo vínculos comerciales, y fundar algunos fuertes en sitios estratégicos que aseguraran la soberanía española ante las potencias enemigas, principalmente frenar la intromisión inglesa (Biedma 1887; Benedicto 1967; Porro 1995; Nacuzzi 2002; Nacuzzi 2005; Bandieri 2005).

El territorio patagónico ha sido uno de los más tardíos apropiados por la Corona Hispánica. Será la coyuntura internacional provocada principalmente por los resultados de la reorganización territorial colonial americana posterior a la Guerra de los Siete Años (1756-1763), la que estimulará el reconocimiento y apropiación de la región sur de Sudamérica por parte de los ingleses y franceses (Zusman 1999). Desde entonces, las coronas inglesa y francesa iniciaron una serie de actividades exploratorias que pusieron sobre aviso a España respecto de la necesidad de reconocer y ocupar las tierras de la Patagonia sudoriental. Esta situación, por lo tanto, aceleró el proceso de avance de la frontera colonial hispánica sobre este territorio (Zusman 1999).

En este marco internacional, los intentos de colonización efectiva se concretaron recién hacia fines del siglo XVIII cuando, según Orden Real firmada en Aranjuez en 1778 por José de Gálvez, Ministro del Rey Carlos III de España, se establecieron tres enclaves en puntos estratégicos: Nuestra Sra. de El Carmen en el Río Negro (Bahía Sin Fondo), es decir en la «entrada» a la Patagonia; su subsidiario en San José en Península Valdés y la Colonia y el Fuerte de Floridablanca en Bahía San Julián, pleno territorio costero patagónico (Biedma 1887; Benedicto 1967; Apolant 1970; Sanguinetti et al. 2005; Senatore 2007, entre otros).

\subsection{La fundación del Fuerte y Poblado de El Carmen}

Como parte de este plan de colonización, Francisco de Viedma exploró por primera vez a comienzos de 1779 la desembocadura del Río Negro, lugar donde fundó el fuerte, a unos $36 \mathrm{~km}$ de la costa atlántica. Inicialmente los expedicionarios lo construyeron sobre la margen sur del río, área inundable, razón por la cual se decidió trasladarlo a su margen norte aprovechando las ventajas que otorgaba la geografía del área, caracterizada por una loma y una alta barranca de roca sedimentaria; así quedó establecido el Fuerte Nuestra Señora de El Carmen y pueblo de Nueva Murcia (Biedma 1887; Levene 1941; De Angelis 1972; Porro 1995; Nacuzzi 2002).

El Carmen fue la única colonia durante este período que logró sobrevivir, en parte por los esfuerzos realizados por Viedma -Comisario Superintendente del poblado desde 1779 hasta 1784- ante el Rey y el Virrey Vértiz para lograr el mantenimiento del paraje, que se convirtió en un enclave fundamental desde donde organizar partidas para efectuar los reconocimientos del Norte de la Patagonia (Nacuzzi 2002, 2005; Bandieri 2005).

\subsection{Los vecinos que convivieron con los colonos}

Para el momento de la fundación del fuerte el área estaba habitada por distintas parcialidades indígenas, principalmente tehuelches (o «patagones»). Estos grupos indí- 


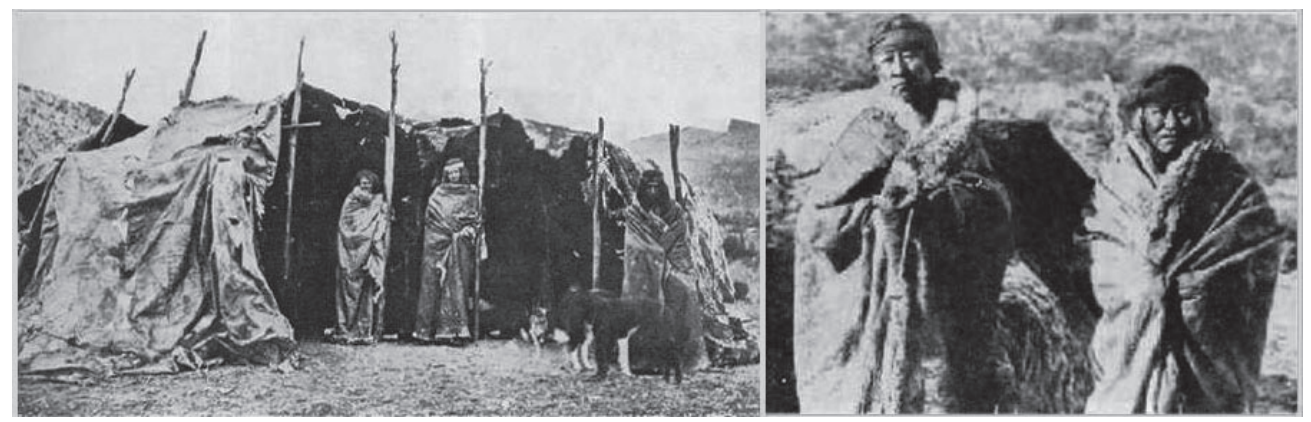

Figura 2: Pobladores tehuelches de la Patagonia.

genas se caracterizaban por ser nómades y cazadores ecuestres, habitualmente instalaban en las inmediaciones del fuerte sus tolderías conformadas por 30/40 toldos (tiendas hechas con cueros) (Figura 2). El naturalista francés Alcide D'Orbigny, describió las características sociales del Carmen durante su estadía entre 1828 y 1829 , así relata sus impresiones: «... el 18 de febrero (1828), día que fijé para ir a visitar a los indios establecidos del otro lado del río. Había tres tolderías...: una de los puelches y patagones, ubicada cerca del caserío; una segunda, más alejada, donde vivían los aucas o araucanos, y una tercera, mucho más importante, de patagones o tehuelches, a las órdenes de un cacique llamado Churlakin...» (D’Orbigny 1999: 299).

Los indígenas del lugar, a través de sus caciques, establecían un contacto continuo con los militares del fuerte e intercambiaban productos de elaboración propia y ganados (caballos y vacas cimarrones) por productos manufacturados por los blancos (aguardiente, azúcar, tabaco, yerba mate, regalos, etc.) (D’Orbigny 1999; Nacuzzi 2002; Bustos e Irusta 2005). «Los jefes indios comenzaron a desempeñar inmediatamente un papel clave en el abastecimiento de la incipiente población y en el manejo de las informaciones sobre los grupos vecinos y la geografía, ambos desconocidos e imprevisibles para los españoles» (Nacuzzi 2002: 43).

D'Orbigny detalla el panorama social del Carmen diciendo que sus habitantes: «... pueden ser unos quinientos a seiscientos, consistentes en los primeros fundadores, agricultores o estancieros, casi todos provenientes de las montañas de Castilla; en gauchos exiliados por sus crímenes y en negros esclavos, empleados como peones en diversas explotaciones...» (D'Orbigny 1999: 546), este relato da cuenta de la heterogeneidad social que identificó a este paraje desde sus primeros años de existencia.

\section{La inmigración española hacia El Carmen}

$\mathrm{Al}$ momento de la fundación y para llevar adelante el plan de colonización de la Patagonia, se utilizó un sistema de reclutamiento inédito, la política borbónica instauró «la contrata de familias» (familias que recibirían un salario como recompensa a su obligación de poblar y hacer productivos los lugares a los que fueran destinados). Este plan no establecía cuándo se les haría entrega de las tierras en carácter de propiedad, ni dejaba espacio para el regreso al lugar de origen. Ambos aspectos desmotivaron a los migrantes gallegos a embarcarse en este proyecto poblacional. El quiebre 
con las pautas migratorias tradicionales, llevó a que el proyecto tuviera poco atractivo para la población de Galicia, epicentro primigenio del llamamiento. Por esta causa, la Corona española extendió la convocatoria a las provincias de Asturias y Castilla y León (Apolant 1970; Zusman 1999; Porro 2005; De Cristóforis 2006).

Es así como, en 1778, se publicó en España un bando ofreciendo a aquellas familias dispuestas a poblar la Patagonia: tierras, semillas, instrumentos y salarios que les permitieran vivir en estas tierras. El Sr. Jorge Astraudi fue el comisario colector, encargado de contratar a las familias en el puerto de La Coruña, Galicia; éste recibió orden de reunir 200 familias pobres de labradores y artesanos «bien instruidas en las labores del campo» para servir de buen ejemplo a los indígenas. Preferentemente debían ser hombres casados o bien solteros hábiles. Estas familias viajarían por cuenta del tesoro real y recibirían un año de manutención (Porro 2005: 23).

Sabemos que para los momentos migratorios tempranos, los migrantes no tenían una gran claridad acerca de un destino rioplatense (Porro 2005: 13), una vez arribados a esta región, las fronteras nacionales se desplazaban sin cesar a causa de movimientos internos (Devoto 2004). Este fue el caso de las familias que participaron del Plan Patagónico; de las 1921 personas que, entre hombres, mujeres y niños, partieron desde el puerto de la Coruña, solamente se destinaron 134 al Fuerte del Río Negro (El Carmen). Hubo una serie de malos entendidos entre la Corona, las autoridades virreinales y los pedidos de familia de Francisco de Viedma; sumado a esto, se produjo el abandono de las colonias de San José y Floridablanca y la consecuente reubicación y desplazamiento de su población durante este período.

Por iniciativa del Virrey Vértiz, un gran porcentaje de las familias que quedaron desamparadas y/o debieron trasladarse hacia otros destinos, fueron derivadas a distintas localidades de la provincia de Buenos Aires y de la Banda Oriental del Río de La Plata -hoy República Oriental del Uruguay- (Apolant 1970).

Entonces, y volviendo a nuestro caso particular, como parte de este plan arribaron al Río de La Plata y, por consiguiente, en similar proporción a El Carmen, familias de gallegos $(25,2 \%)$, asturianos $(33,1 \%)$ y, principalmente, castellano-leoneses $(41,7 \%)$ (Biedma 1887; Ramos 1982; Porro 1995: 84), se sabe que entre ellos habrían llegado varios maragatos (Biedma 1887: 18; Benedicto 1967: 6).

\section{La sociedad de El Carmen durante las primeras décadas}

La población de El Carmen se caracterizó, durante los primeros años luego de la fundación, por ser una población heterogénea, tal vez esta razón y el hecho de tener un origen ibérico común, llevó a que las familias españolas conformaran un grupo socialmente ceñido, estableciendo relaciones casi únicamente entre ellas; por supuesto esta actitud hizo que sus tradiciones, poco alteradas, perduraran en el tiempo. En el año 1828 A. D'Orbigny comentó sorprendido: «... Durante mucho tiempo esos primeros habitantes (refiriéndose a los llegados desde España -la aclaración es nuestra-), aislados del resto de América, conservaron su acento y costumbres primitivas; y en la época en que yo estuve era fácil distinguir a los primeros fundadores» (D'Orbigny 1999: 518). Debemos recordar que esta impresión fue registrada casi medio siglo después del primer desembarco. 
Esta actitud condujo a una marcada endogamia, ya Juan Cruz Jaime (2001) en su estudio acerca de los fundadores de Carmen de Patagones, manifiesta que durante los primeros momentos la endogamia se hizo más intensa y los parentescos fueron múltiples. En la primera generación, este grupo de colonos en su mayoría ya venían casados y con algunos hijos pequeños. Muchos de ellos enviudaron a poco de llegar y comenzaron a formar el tejido social que prevaleció durante todo el siglo XIX (Jaime 2001). Durante la segunda generación el horizonte comienza a abrirse lentamente, se originaron algunos matrimonios entre las familias españolas importantes con oficiales de alta graduación. Asimismo, se favoreció el matrimonio con los corsarios ingleses y alemanes que convivían con los habitantes de Patagones.

La endogamia, factor fundamental durante la segunda y tercera generación, no podría haber existido de no realizarse gran cantidad de matrimonios cruzados - esto es, varios hermanos de una familia con varias hermanas de otra- entre los hijos de los fundadores. Es recién durante la cuarta generación que los habitantes fundadores de Patagones comenzaron a aceptar los matrimonios con los hijos de los inmigrantes italianos que estaban asentados en Carmen desde 1855 (Jaime 2001).

Si resaltamos algunas de las características de los maragatos en su tierra de origen, podremos notar coincidencias en cuanto a las costumbres endogámicas. Una de las decisiones más importantes de la familia maragata llegaba al momento de colocar a los hijos en estado matrimonial, de esta decisión dependía tanto la permanencia del apellido y la posición social de la familia, como también las posibilidades futuras de las nuevas familias y unidades productivas arrieras. Desde esta perspectiva se entiende que desde un principio la sociedad maragata se cerrase al exterior mediante la combinación de tres tipos de endogamia: la familiar, la geográfica y la profesional (Rubio 2003: 56). Si bien resaltamos que este grupo no fue el único que emigró hacia El Carmen, pudo su influencia ser destacada en la organización social del grupo fundador emergente.

Años más tarde, esta fuerte consolidación «étnica» hispana originó un enfrentamiento con las autoridades patriotas. Después del establecimiento el primer gobierno Patrio en 1810 (seguido por la Independencia nacional en 1816), este grupo español, al no reconocer a las nuevas autoridades y sus medidas de liberación, llegó a provocar una sublevación realista en $1812^{5}$, la que determinó la desvinculación de Patagones con la ciudad de Buenos Aires hasta Diciembre de 1814, dependiendo de Montevideo hasta la caída de esta plaza en Junio del mismo año (Bustos 1989: 37).

Luego de este episodio y ya reestablecido el orden en este puerto patagónico, la contienda con Brasil en $1827^{6}$ unificó y organizó otra vez a aquellos colonos; gracias a su ordenación interna, coraje y orgullo de pertenencia, pudieron hacer frente a la amenaza

\footnotetext{
5 Durante este período flameó la bandera española en los mástiles de Nuestra Señora de El Carmen, en lugar de las insignias de la nueva patria.

${ }^{6}$ La guerra argentino-brasileña fue el último acto de un antiguo conflicto entre España y Portugal, que se remontaba al siglo XVI, por la posesión de los actuales territorios de la República Oriental del Uruguay y parte del estado de Río Grande do Sul en Brasil. La guerra se desató el 10 de Diciembre de 1825, cabe destacar que Brasil acababa de emanciparse de Portugal. Este enfrentamiento derivó en el bloqueo del puerto de Buenos Aires por la armada Imperial, por lo tanto se recurrió al puerto de Patagones como alternativa. Así la batalla llegó a este pueblo patagónico, el que el 7 de marzo de 1827 enfrentó a las fuerzas enemigas y con la colaboración de todo la población, corsarios y militares lograron un triunfo contundente (Bustos e Irusta 2005).
} 
del enfrentamiento externo en el puerto de El Carmen. Aunando sus fuerzas a las de los militares del fuerte, los corsarios y los negros «libertos», lograron vencer al enemigo, dando origen al gran hito histórico de Patagones. Para entonces ya se hablaba de la fuerza, el coraje y el honor de los vecinos españoles (Bustos e Irusta 2005: 5).

Todas estas actitudes de los pobladores hispanos durante las primeras décadas, dieron como resultado el surgimiento de un grupo de élite que socialmente conformó una pequeña «nobleza e hidalguía» y ocupó los estamentos sociales más altos, mientras que políticamente obtuvieron los puestos de mayor envergadura (idea que surge de la bibliografía y de los comentarios extraídos de las entrevistas realizadas entre especialistas en la materia y distintos vecinos estudiosos de la historia del paraje [2008 y 2010]).

Las características endogámicas, así como de fuerte pertenencia grupal, el orgullo por la ascendencia hispana y el destacado nivel que ocuparon en el ámbito social y político, hizo que los fundadores dejaran una huella perpetua en esta ciudad. Es un hecho que la impronta que legaron los colonos españoles, y los maragatos entre ellos, ha marcado de forma definitiva y singular tanto la historia como la identidad del lugar.

\section{Las cuevas de la costa del río Negro}

Si bien la historia de esta inmigración pasó, a lo largo de las primeras cinco décadas, por diferentes circunstancias, lo cierto es que hoy el nombre maragato está asociado al momento de su instalación en las famosas «cuevas maragatas».

El origen de estas cuevas se remonta al momento de la llegada y se asocia a la carencia de medios económicos básicos. La historia nos cuenta que al arribar a destino las familias españolas se enfrentaron con la ausencia de los recursos prometidos y el consiguiente incumplimiento de las autoridades (Biedma 1887; Apolant 1970; De Cristóforis 2006), por lo tanto los primeros colonos no tuvieron acceso a los materiales necesarios para la construcción de sus habitaciones. A falta de maderas de bosques abundantes y piedras en los alrededores y ante la necesidad imperiosa de cobijo, aprovecharon el paisaje y lo poco que les brindaba: la costa abarrancada de arenisca; esta característica geográfica les permitió labrar cuevas o ampliar las ya existentes e instalarse en ellas durante años (Biedma 1887; Ramos 1982; D`Orbigny 1999 [1846]; Musters 2005 [1911]).

Con el correr de los años las cuevas labradas por los primeros pobladores se fueron perfeccionando y haciendo más aptas para una supervivencia más confortable. Las casas recién comenzaron a levantarse a fines del siglo XVIII, cuando ya habían transcurrido casi veinte años desde la llegada de los primeros pobladores. Pero esto no significó que las cuevas fueran abandonadas, ya que fueron habitadas por nuevas familias, especialmente de escasos recursos. Aún durante la segunda mitad del siglo XIX se vendían y alquilaban cuevas en Patagones. Actualmente se observan antiguas casas que aún conservan en el barranco del fondo del patio, las clásicas cuevas maragatas (Nozzi 1983). A comienzos del siglo XX las cuevas estaban deshabitadas casi en su totalidad, muchas de ellas se habían derrumbado, otras fueron reforzadas por sus dueños con muros y bóvedas de ladrillos para evitar su derrumbe. 


\section{Rastreando tradiciones maragatas}

La filiación maragata, más allá de los 231 años de la llegada de los primeros campesinos españoles, se manifiesta férreamente en el gentilicio con el que se identifica toda la población actual; vemos esta identificación en las autorreferencias de los vecinos, en los letreros de los comercios de la ciudad (Tienda de tejidos «Tricot Maragato»), en los nombres de los grupos de actividades («Grupo de hilanderas maragatas»), en la referencia de los primeros viajeros que visitaron este enclave histórico y en los expedientes judiciales y libros desde mediados del siglo XIX.

Históricamente, tanto las características sociales como los vaivenes político-económicos de El Carmen, han sido altamente estudiados y la bibliografía al respecto es notoriamente abundante, sin embargo, muy poco se sabe de la vida cotidiana de aquellos colonos, de las vicisitudes «puertas adentro».

Para acercarnos al ámbito privado propusimos una mirada multidisciplinaria, gracias a la cual aplicamos en esta investigación las herramientas teórico-metodológicas que nos ofrecen la Historia, la Arqueología y la Antropología. El aporte de cada una de estas ciencias nos permite ir armando el rompecabezas social de entonces.

Desde la Antropología ${ }^{7}$, ciencia que nos facilita el conocimiento profundo de tradiciones e idiosincrasias, pudimos acceder en primera instancia, a los estudios existentes acerca de la arquitectura tradicional de la Maragatería. Esta se caracteriza por grandes casas de piedra erigidas como pequeñas fortalezas, que resguardaban tanto la intimidad de la familia como los bienes que estos arrieros comerciaban. Edificadas principalmente por la burguesía maragata durante la época de su mayor esplendor socio-productivo (Rubio 2003), son el fiel reflejo de la solidez económica alcanzada durante los siglos XVIII y XIX y de la personalidad sosegada y discreta de las familias arrieras campesinas. Aunque, a la hora de comparar los lugares de habitación a ambos lados del océano Atlántico, las diferencias son muy evidentes, ciertas características de la personalidad maragata tanto como determinadas destrezas de construcción, pudieron haber facilitado la conformación de las cuevas de Carmen y la supervivencia en ellas durante años.

Inclusive las características arquitectónicas de los caserones de la Maragatería -pocas y pequeñas ventanas y una única gran puerta de acceso para animales y personaspensadas para mantener la intimidad familiar y económica, facilitaron la costumbre de vivir con poca luminosidad y una deficiente circulación de aire al interior de la vivienda, características que también distinguen a una cueva. Tal vez los maragatos, al estar ya habituados a estos contextos sombríos, mostraron mayor predisposición para habitar estas moradas de arenisca y perdurar en ellas, aunque tuvieran que hacerlo de forma precaria y austera.

${ }^{7}$ El intercambio bibliográfico y académico con destacadas instituciones e investigadores españoles (como fue el caso del Profesor José Luis Alonso Ponga, Director de la Cátedra de Estudios sobre la Tradición, de la Universidad de Valladolid; María Isabel Martínez Navarrete, Científica titular del Instituto de Historia del Centro de Ciencias Humanas y Sociales, CSIC, Madrid; y la colección maragata del Museo del Traje de Madrid), nos aproximó, a través de su cultura material e inmaterial, tanto al presente como a la historia de los maragatos en sus tierras de origen. 
Desde la Historia Oral, disciplina que facilita y permite el acceso a las memorias, recuerdos y costumbres (Bertaux 2005), se tomó contacto con la raíz maragata y la presencia actual en Argentina, a través del Centro Maragato Val de San Lorenzo de la ciudad de Buenos Aires ${ }^{8}$; sus miembros actuales nos permitieron la profundización en la condición maragata, actual y pasada, así como en su folklore, objetos y sentir. Estas memorias (recopiladas a través de entrevistas, historias de vida y tradición oral) nos orientan, organizan y ayudan en la interpretación de este fenómeno identitario.

Sumamos el aporte fundamental de los habitantes actuales de Carmen, en primera instancia los descendientes de los primeros pobladores, aunque alejados por generaciones de sus antepasados, conservan recuerdos y un interés notorio por su ascendencia, hoy son vecinos de amplia trayectoria y tradición, representantes del grupo aristócrata de entonces.

Luego observamos al resto de los pobladores, que si bien no están relacionados directamente con los españoles del primer momento de ocupación, son un referente del complejo entramado socio-cultural de la población actual y pasada, producto de la convivencia de variados actores sociales provenientes de distintos ámbitos y naciones.

El acercamiento a los vecinos nos ha llevado, a su vez, a la identificación de determinadas costumbres socio-religiosas enraizadas en el momento de la fundación y relacionadas exclusivamente con el grupo español fundacional (y al transcurrir los años, sólo con los descendientes de aquellos), costumbres que se han mantenido hasta hace muy pocos años atrás, como es el caso de «las camareras de la virgen» (Casadei 1996): inicialmente damas maragatas y luego con los años, descendientes genuinas de aquellas; único grupo de mujeres facultadas para cambiar las vestimentas de la Virgen del Carmen (patrona de la ciudad e imagen de vestir) según los distintos pasajes de la liturgia.

Por su lado, la Arqueología, aporta, desde la materialidad de las sociedades pasadas, la posibilidad de una mirada intrínseca de las costumbres y la vida cotidiana, a través de la cultura material aún resguardada en las cuevas que perduran.

\section{Búsqueda material de la presencia maragata}

Hasta el presente la materialidad maragata se reduce a la existencia de las cuevas donde, según el imaginario popular, la tradición oral y las distintas fuentes históricas, vivieron y perduraron los maragatos.

En los Museos locales (Museo Histórico Regional Emma Nozzi y el Museo Antropológico de Viedma), así como en la Asociación Española y Mutualista de Carmen de Patagones, los registros son pobres con respecto al primer poblamiento y las piezas que atesoran, así como los documentos que conservan, nada especifican acerca de los maragatos llegados en los primeros contingentes. Los fondos que conforman las colecciones del museo local (como trajes y calzados típicos maragatos), han ingresado alrededor de 1970, producto de donaciones de inmigrantes maragatos llegados

\footnotetext{
8 Entidad sin fines de lucro fundada en 1924 que congrega a maragatos y descendientes, cuyo objetivo primordial es el mantenimiento y difusión de las costumbres y cultura maragatas.
} 
a Buenos Aires durante el transcurso del siglo XX. Si bien es real la presencia y exposición de objetos españoles de marcada antigüedad, claramente relacionados con los descendientes de los primeros colonos, nada indica aún una relación directa con los objetos tradicionales maragatos que hemos podido estudiar (arracadas -conjunto de joyas-, relicarios, amuletos, prendas de vestir típicas, mantas y cobertores, instrumentos musicales y de labranza).

La población de Nuestra Señora de El Carmen, al haber logrado subsistir y perdurar, a diferencia de las demás colonias del mismo plan fundacional, posee características diferentes que hacen que las labores de reconstrucción histórica del primer asentamiento no sean tarea fácil. No sólo sobrevivió a su fundación sino que logró convertirse en un punto estratégico, centro de innumerables hechos históricos que hicieron a su constante transformación espacial. Este éxito, supervivencia y ocupación continua, hacen que, en la actualidad, la visibilidad arqueológica, al igual que la presencia de cultura material relacionada con el primer asentamiento español, sean muy bajas.

\subsection{Arqueología: las cuevas-hogar}

Nuestro objetivo específico es aportar al conocimiento de los modos de vida y de habitación de los primeros pobladores de Carmen de Patagones; planteamos así un estudio arqueológico que comprendiera, en primera instancia, los espacios de habitación, sus alrededores y la relación de estos con las áreas productivas de aquel momento. Nuestra investigación se inició en el año 2005, sucediéndose hasta el presente varios trabajos de campo (Casanueva et al. 2007; Murgo y Casanueva 2008; Casanueva y Murgo 2008, 2009; Casanueva 2009).

Hoy en día existen cuevas sólo en dos sectores de la ciudad: en el Casco Histórico y en el sector rural de Laguna Grande (ver Figura 1). Ambas áreas trabajadas dieron como resultado datos útiles a los objetivos planteados, especialmente sobre usos del espacio doméstico y técnicas constructivas.

\subsection{Casco Histórico}

La población de Carmen de Patagones se inició en el sector hoy denominado «centro histórico», sobre la faja de terreno abarrancado de 20 metros de desnivel y 150 de ancho, entre el antiguo emplazamiento del Fuerte y la orilla del río Negro; allí como en una gradería de tres tramos, se definieron dos calles longitudinales en el sentido de la costa, éstas son Biedma (antes calle de la Ribera) a $5 \mathrm{~m}$ de altitud promedio y la calle Mitre (antes calle Real) con una elevación media de 12 a 14 m sobre el nivel del mar (De Paula 1991).

En el sector más antiguo del pueblo, observamos actualmente cuevas tanto en los fondos de propiedades deshabitadas como habitadas, estas últimas continúan en uso cumpliendo funciones de almacenamiento y/o corrales para animales pequeños (Figura 3). Todas estas estructuras son de una única cámara variando notoriamente de tamaño: entre 10 y $30 \mathrm{~m}^{2}$. Inclusive en algunos casos algunas han sido subdivididas posteriormente y han ido sufriendo modificaciones estructurales importantes: el piso 
Figura 3: Cueva en el Casco Histórico de Carmen de Patagones, ubicada en el patio de una propiedad privada (Fotografía de la autora).

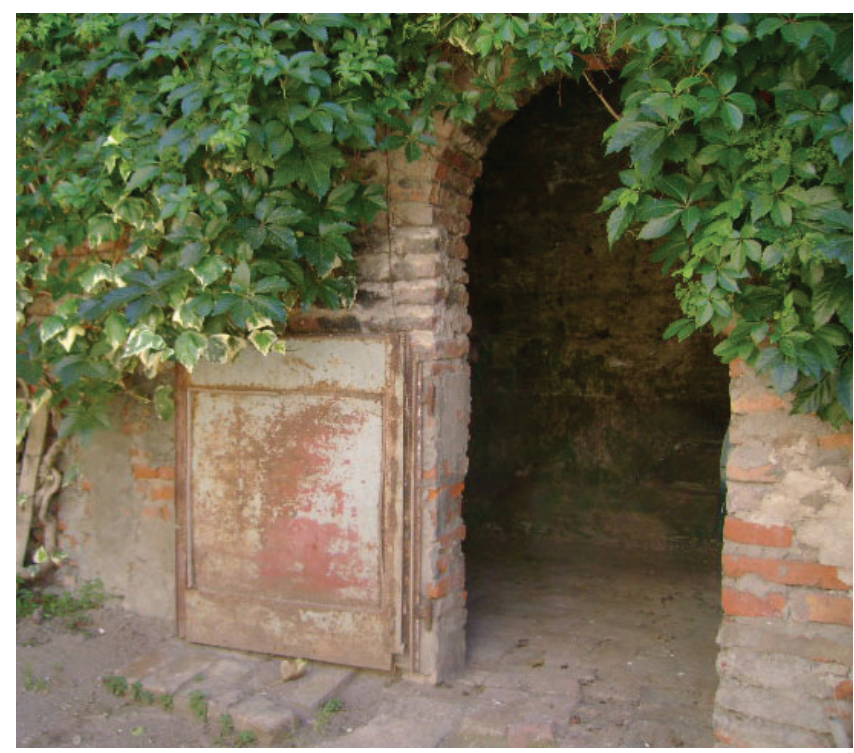

de tierra original cubierto por ladrillos, paredes apuntaladas con ladrillos y vigas en los techos, agregado de puertas, etc.

Muchas de las cuevas de este sector se encuentran tanto en espacios de protección patrimonial como en propiedades privadas. Mencionamos las existentes y visitadas hasta el momento: Cueva del Museo Histórico Regional Emma Nozzi; Cueva de La Casa de la Cultura, Cueva del Rancho Rial y Cueva de la calle Bernardino Rivadavia, las tres bajo la protección de la Dirección de Patrimonio Histórico; Predio de la antigua Cofradía de las Ánimas (el edificio de principios del siglo XIX, hoy desaparecido, ha dejado al descubierto el murallón de arenisca del fondo del terreno, en donde quedan rastros de posibles cuevas) y por último cuevas en los fondos de los patios de vecinos particulares, que habitan el área abarrancada.

Hasta el presente, las cuevas recorridas en el Casco Histórico -más allá de la constante modificación, visita, remoción y utilización por parte de la población y visitantes-, aún albergan (escasos) restos de la vida cotidiana transcurrida en ellas, encontramos algunos fragmentos en superficie de: antiguos envases de vidrio (botellas y frascos) así como vajilla de loza (siglo XIX). Estos restos se complementan con los objetos hallados por generaciones de propietarios de cuevas o habitantes del casco histórico, circunscriptos fundamentalmente al área de la barranca. Nos han mencionado (hemos podido observar sólo algunos de ellos): recipientes contenedores y porrones de ginebra de gres, antiguos envases de vidrio tanto de bebidas alcohólicas como frascos de farmacia y perfumería, añejos tapones de electricidad de porcelana, fragmentos de vajilla de loza, llaves, botones, clavos, etc.; todos objetos cuya antigüedad se remonta al siglo XIX; asimismo, entre estos objetos se han encontrado algunos elementos de raigambre indígena como instrumentos en piedra, tanto para la molienda y procesamiento de alimentos, como relacionados con la caza y la defensa (hoy en colecciones privadas). 


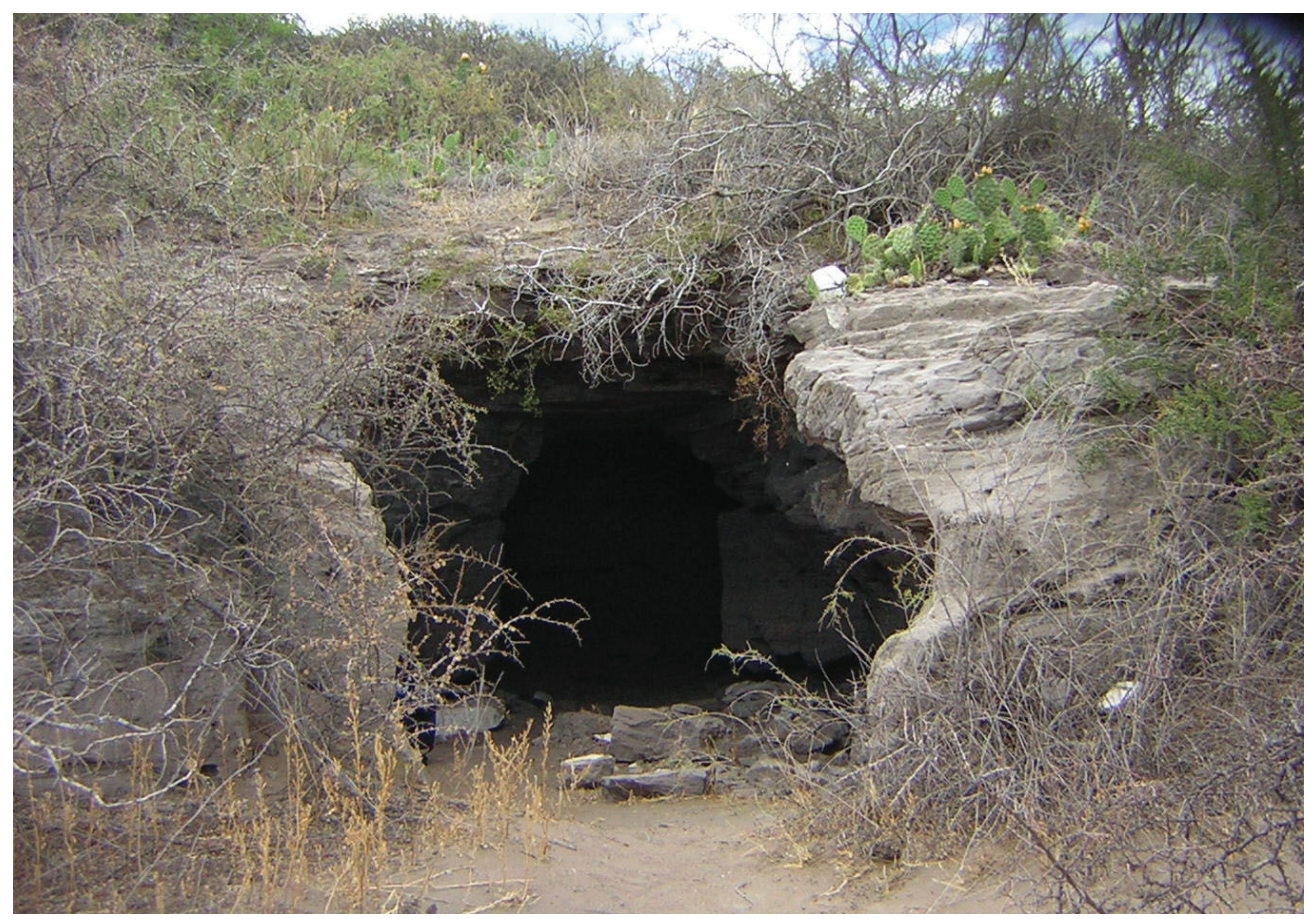

Figura 4: Cueva Maragata CM1 en el área rural de Laguna Grande (Fotografía de la autora).

Era esperable esta convivencia de objetos disímiles, debido a la utilización continua de la barranca del río desde tiempos inmemoriales por las distintas y abundantes parcialidades indígenas y luego por la población relacionada con el Fuerte y el consiguiente Poblado.

\subsection{Laguna Grande}

Área de producción conformada por chacras y quintas distante a unos $7 \mathrm{~km}$ del centro de Carmen y paralela al curso del río Negro; este sector ha sido poblado desde el momento mismo de la fundación (Bustos 1989: 15). Aquí se conocen sólo dos cuevas, ambas también cavadas en la arenisca rionegrense, ubicadas sobre una loma que se eleva paralela al actual cauce del río y frente a la antigua Laguna Grande (hoy sin agua) (Murgo y Casanueva 2008).

En este sector efectuamos una combinación de prospecciones pedestres, relevamiento fotográfico y planimétrico, recolección en transectas de materiales de superficie y realización de sondeos selectivos en todas las cámaras de las cuevas y en sectores colindantes.

Las dos cuevas que aquí existen (hoy bajo la protección de la Dirección de Patrimonio Histórico de Patagones) han sido llamadas por nosotros Cueva Maragata 1 (CM1) (Figura 4) y Cueva Maragata 2 (CM2); estas dos estructuras revisten características diferentes a las del Casco Histórico ya que cuentan con varias cámaras 

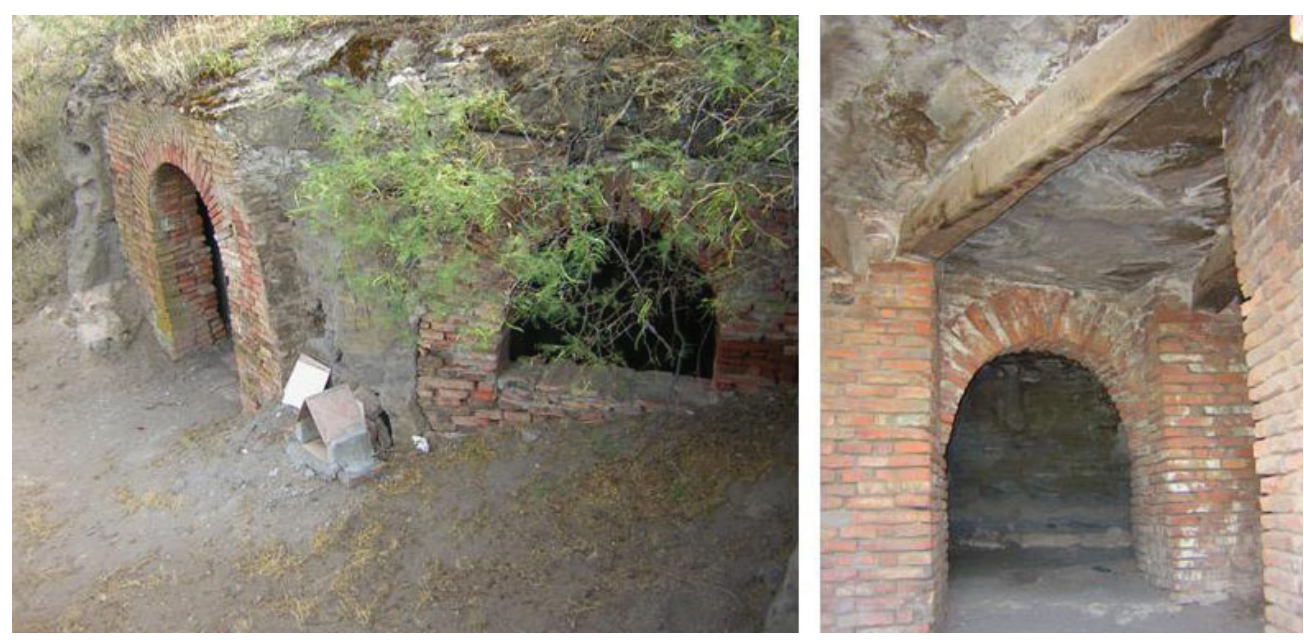

Figura 5: Cueva Maragata CM2, vista exterior y detalle del apuntalamiento de techos y paredes en sus cámaras internas (Fotografías de la autora).

(entre 3 y 5), sus dimensiones varían entre 35 y $45 \mathrm{~m}^{2}$, una de ellas (CM2) presenta un revestimiento externo e interno de ladrillos, un apuntalamiento de techos con fuertes vigas de madera, un vano de acceso y una ventana lateral, todas modificaciones hechas en momentos posteriores a su labrado original (Figura 5).

\subsection{Vida en las cuevas de Laguna Grande}

Los hallazgos, hasta el presente, nos permiten hablar de ciertas actividades domésticas y pautas de consumo, tanto en estratigrafía como en superficie, encontramos: fragmentos vítreos de antiguas botellas de cerveza, vino y Hesperidina (bebida alcohólica a base de hierbas de marca nacional «Bagley»), entre estos fragmentos se destaca un grueso cuello de botella negra inglesa de cerveza, confeccionado artesanalmente, con pico aplicado a mano (ubicado entre finales del siglo XVIII y las primeras décadas del siglo XIX); el vidrio también está representado por un fragmento de vaso grueso acanalado y un fragmento de frasco de farmacia lila de paredes espesas (Rock 1981; Jones y Smith 1985; Schávelzon 1991; Jones 2000). La vajilla está presente en escasos fragmentos de loza inglesa (Whiteware y Pearlware) y dos fragmentos de teja «muslera» (teja hecha artesanalmente sobre el muslo del artesano) (Schávelzon 1991, 2001); ciertos elementos de hierro hallados en una especie de escondrijo en una de las cuevas, podría indicarnos la relación de estas viviendas con las labores de producción: se hallaron dos grandes clavos de hierro y un «atador de alambre» de poste de alambrado; mientras que algunos restos faunísticos de oveja (Ovis aries) y mamífero pequeño indeterminado (asociados todos a carbones) nos acercan a las elecciones a la hora del consumo de carne animal y también nos hablan de la producción local. 


\section{1. ¿Por qué maragatos?}

Mientras la arqueología aún no ha ofrecido pruebas materiales claras e inequívocas del primer origen maragato, las fuentes escritas indican que los maragatos no fueron el grupo más numeroso llegado a estas tierras. Sin embargo, la ciudad y la región tomaron su nombre de ese grupo reducido de inmigrantes leoneses: la comarca maragata.

Quizás debamos explicar la fuerza de este patronímico ${ }^{9}$ en las propias características de este grupo humano, arrieros y comerciantes en tierra de origen, pudieron valerse de sus conocimientos y las habilidades que seguramente les confirió esta actividad, para ocupar con éxito el nuevo territorio y hacerse conocidos en el resto de la Patagonia gracias a ella. Tengamos en cuenta que este enclave patagónico, ubicado sobre la frontera interna más austral del territorio, fue un centro comercial, de intercambio y estratégico de extremada importancia, en el que probablemente los maragatos, aprovechando sus oficios y conocimientos de mercaderes y viajantes, cumplieron un rol protagónico en la dirección de las transacciones comerciales del poblado.

Asimismo, esta actividad comercial debió entrenarlos en la interacción social con diferentes grupos humanos dentro de la península Ibérica y conferirles una organización interna que ayudó a que mantuvieran su definición como grupo en la nueva fundación. Quizás estas características los facultaron para liderar y destacarse en el nuevo entorno y hacer frente a las situaciones adversas, aportando la organización necesaria para asentarse en el desconocido territorio: «...La influencia de estos pobladores (los maragatos) fue decisiva en los modos de convivencia de la naciente comunidad. La estructura social de Carmen de Patagones, está penetrada por el espíritu de estos colonos, razón por la cual hoy se denomina maragatos a los nacidos en la ciudad de la margen norte del Río Negro» (Benedicto 1967: 6). Así el gentilicio maragato comenzó a extenderse en el espacio y en el tiempo.

En cuanto a su relación con las cuevas-hogar. Pensamos que determinadas características idiosincráticas, así como el carácter excéntrico y apesadumbrado y ciertas costumbres de habitación, pudieron haber facilitado la vida de los maragatos en las cuevas de Patagones. Distintas fuentes enfatizan que fueron estos los que continuaron utilizándolas aún en momentos donde las casas habían comenzado a ser levantadas (Bustos 1989) y el poblado contaba con mayores medios económicos. Tal vez, desde esos momentos y por estas circunstancias, en la actualidad, siempre se recuerde y asocie estas habitaciones con los maragatos.

\section{Palabras finales}

Las cuevas. Son varias las características que determinan a estos espacios de habitación como únicos, convirtiéndolos en uno de los reservorios histórico-arqueológicos

\footnotetext{
9 Sabemos que para el siglo XVIII los procedentes de la Península Ibérica no se reconocían como españoles, sino que se nombraban según su lugar de origen; de aquí el grupo identificado con la Maragatería, propició la difusión del gentilicio maragato.
} 
más importantes de la región patagónica y de la República Argentina. Estas estructuras domésticas y de habitación, que si bien no son exclusivas de Patagones, se destacan, en primera instancia, por su gran escala cuantitativa y distributiva a lo largo de todo el paisaje costero; asimismo sobresalen por su utilización continua desde el momento de la fundación hasta el presente. Aquí hacemos énfasis en el aporte de la arqueología, ya que la cultura material hallada en las cuevas nos aproxima a la vida de las personas que las habitaron a lo largo de los años. Los hallazgos dentro de estas estructuras y en sus alrededores, nos remiten al período que va desde los últimos años del siglo XVIII hasta el siglo XX, período durante el cual estos espacios estuvieron habitados y/o utilizados, estos hallazgos son indicadores de la continuidad en el uso del espacio; asimismo, dan cuenta de determinadas actividades domésticas, labores de producción y tareas relacionadas con el mantenimiento estructural de las habitaciones.

Varias de estas estructuras presentan aún un buen estado de conservación, particularidad que alienta y propicia su investigación y registro. Consideramos, a su vez, que el momento actual de estudio es clave, ya que las características de fragilidad y friabilidad propias del material constructivo (arenisca), las condiciones climáticas actuales de incipiente desertización y el auge acelerado de remodelación arquitectónica y edilicia del poblado, nos alertan ante actuales y futuros desmoronamientos y drásticas desapariciones.

Los maragatos. Es un hecho que los maragatos tuvieron real importancia y participación durante la gesta fundacional. No sabemos si todos los nacidos en Carmen se sienten, en la actualidad, identificados con el gentilicio maragato, sin embargo, sea ésta una identidad impuesta o no, y aunque su significado no sea el mismo en la Maragatería que en Carmen de Patagones, ni la raíz rememore la misma idiosincrasia, el nombre maragato se mantiene firme en pleno siglo XXI en ambas márgenes del Atlántico. No es tan importante saber si este gentilicio sólo recuerda la gesta poblacional o si enarbola el mito de los siglos de oro de los arrieros de León, es importante sí, notar que este gentilicio perdura en Argentina, aún hoy, con una fuerza inalterada y contribuye a la vigencia histórica del grupo social que lo popularizó, tanto nombrándolos como atribuyéndoles las ruinas históricas más representativas de la ciudad.

Agradecimientos: Muy destacadamente agradezco a la Dra. Cecilia Pérez de Micou. A mi compañera y Codirectora del Proyecto Arqueológico del Partido de Patagones, Lic. Andrea Murgo; al Licenciado Jorge A. Bustos y al personal del Museo Histórico Regional Emma Nozzi; a la Arq. Mónica Herrero, Directora de Patrimonio Histórico de Patagones, a Cesar Negro y Laura Sabesinsky, de esta misma Institución; a la Comisión Directiva de la Asociación Española Mutualista y Cultural de Patagones; a todos los vecinos de Carmen de Patagones; a Trinidad Valle, Enrique San Martín y Comisión Directiva del Centro Maragato Val de San Lorenzo de Buenos Aires. En España, mi especial agradecimiento a María Isabel Martínez Navarrete (Científica titular del Grupo de Investigación Prehistoria Social y Económica del Instituto de Historia, Centro de Ciencias Humanas y Sociales, CSIC, Madrid) y a José Luís Alonso Ponga (Director de la Cátedra de Estudios sobre la Tradición, Centro de Antropología Aplicada, Universidad de Valladolid); asimismo a Andrés Carretero Pérez (Director del Museo del Traje de Madrid). 


\section{Referencias bibliográficas}

Apolant, Juan Alejandro

1970 Operativo Patagonia. Historia de la mayor aportación demográfica masiva a la Banda Oriental. Montevideo: Imprenta Letras S. A.

BANDIERI, Susana

2005 Historia de la Patagonia. Buenos Aires: Editorial Sudamericana.

Benedicto, Carlos N.

1967 Páginas de historia. Carmen de Patagones. Viedma: Dirección de Prensa del Gobierno de Río Negro.

Bertaux, Daniel

2005 Los relatos de vida. Perspectiva etnosociológica. Barcelona: Bellaterra.

BiAnChI Villelli, Marcia

2007 «¿Espacios de cambio social? Los espacios no proyectados por la corona en la población española de Floridablanca (San Julián, Siglo XVIII)», en Arqueología de Fuego-Patagonia. Levantando piedras, desenterrando huesos y develando arcanos, pp. 787-799. Punta Arenas: Ed. CEQUA.

BIEDMA, José J.

1887 Apuntes históricos del Río Negro: seguidos de una brevísima reseña de sus importantes pueblos. Viedma: Colección Biblioteca J. J. Biedma, AGN.

Bustos, Jorge

1989 Economía y poblamiento del Valle Inferior del Río Negro. Tesis de Licenciatura inédita. Universidad Nacional del Comahue, Viedma.

Bustos, Jorge y Jorge IRUSTA

2005 El Combate de Patagones. Carmen de Patagones: Museo Histórico Regional Emma Nozzi - La Lámpara Ediciones Artesanales.

CASAdei, María Cristina

1996 Romancero de Sur y Viento. Carmen de Patagones: Casa de la Cultura - Municipalidad de Patagones - Dirección Municipal de Cultura.

Casanueva, María Laura

2009 «Colonizando la Patagonia: Las primeras viviendas de Carmen de Patagones a finales del siglo XVIII». Novedades de Antropología. Boletín informativo del Instituto Nacional de Antropología y Pensamiento Latinoamericano 18 (63): 7-11.

Casanueva, María Laura y Andrea Murgo

2009 «Primeros pobladores españoles en el Fuerte-Poblado de El Carmen, Patagonia argentina (finales del siglo XVIII)». Revista de Arqueología Histórica Argentina y Latinoamericana 3: 19-46.

2008 «Inmigrantes «maragatos» en Carmen de Patagones a fines del siglo XVIII. Los aportes de la Arqueología y la Historia», en Libro de Resúmenes del V Congreso de Arqueología de la Región Pampeana, pág. 80. Santa Rosa, La Pampa.

Casanueva, María Laura, Andrea Murgo y Diego Aguirre

2007 «Arqueología del Sector Centro-Sur del Partido de Patagones y el uso de las fuentes escritas como primera aproximación a su estudio», en Signos en el tiempo y rastros en la tierra, Mariano Ramos y Eugenia Néspolo, comps., vol. 2, pp. 229-237. Luján: Universidad Nacional de Luján. 
De Angelis, Pedro

1972 «Reconocimiento del Río Negro y de los puntos adyacentes de la costa patagónica por el Coronel D. Ambrosio Crámer», en Colección de obras y documentos, pp. 1153-1160. Buenos Aires: Editorial Plus Ultra.

De Coninck, Fréderic y Francis Godard

1998 «El enfoque biográfico a prueba de interpretaciones», en Los usos de las historias de vida en las ciencias sociales, II, Thierry Lulle et al., coords., pp. 259-291. Rubí - Santa Fe de Bogotá: Antrophos - Centro de Investigaciones sobre Dinámica Social de la U. Externado de Colombia.

De CRISTÓForis, Nadia

2006 «Ideas y políticas migratorias españolas a fines del Antiguo Régimen: el caso Astur-Galaico». Anuario de Estudios Americanos 63 (2): 117-150.

De Paula, Alberto

1991 Carmen de Patagones y su expansión urbana, 1854-1889. Carmen de Patagones: Archivo y Museo Históricos del Banco de la Provincia de Buenos Aires «Doctor Arturo Jauretche».

Devoto, Fernando

2004 Historia de la inmigración en la Argentina. Buenos Aires: Editorial Sudamericana.

D'Orbigny, Alcide

1999 Viaje por la América Meridional II [1846]. Buenos Aires: Emecé.

JAIME, Juan Cruz

2001 «Apuntes sobre los fundadores de Carmen de Patagones». Tiempos Patagónicos 3 (5). Documento electrónico, http://www.uca.edu.ar/esp/sec-pigpp/esp/docs-estudios/revista/tp5/carmen.pdf, con acceso el 29 de abril de 2013.

JoNES, Olive

2000 «Glass Bottle Push-ups and Pontil Marks», en Approaches to material culture research for historical archaeologists, David R. Brauner, comp., pp. 149-160. Society for Historical Archaeology.

Jones, Olive R. y Ann Smith

1985 Glass of the British military - 1755-1820. Ottawa: Minister of Supply and Services.

LEVENE, Ricardo

1941 Historia de la Provincia de Buenos Aires y formación de sus pueblos, vol. 2. La Plata: Archivo Histórico de la Provincia de Buenos Aires.

Murgo, Andrea y María Laura CAsanueva

2008 «Arqueología histórica del partido de Patagones (Prov. de Bs. As.). Resultados iniciales de los trabajos de campo», en Continuidad y cambio cultural en Arqueología Histórica, María Teresa Carrara, comp., pp. 385-394. Santa Fe: Universidad Nacional del Rosario.

Musters, George

2005 Vida entre los Patagones [1911]. Buenos Aires: El Elefante Blanco.

NACUZZI, Lidia R.

2002 «Francisco de Viedma: un cacique blanco en tierra de indios», en Funcionarios, diplomáticos, guerreros. Miradas hacia el otro en las fronteras de Pampa y Pata- 
gonia (siglos XVIII y XIX), Lidia Nacuzzi, comp., pp. 25-64. Buenos Aires: Sociedad Argentina de Antropología.

2005 Identidades impuestas. Tehuelches, aucas y pampas en el norte de la Patagonia, $2^{\mathrm{a}}$ edición. Buenos Aires: Sociedad Argentina de Antropología.

Nozzi, Emma

1983 Informe de las cuevas maragatas urbanas. Carmen de Patagones: Archivo y Museo Históricos del Banco de la Provincia de Buenos Aires «Doctor Arturo Jauretche».

Porro Gutiérrez, Jesús María

1995 La inmigración asturiana y castellano-leonesa para el poblamiento de la Patagonia en época de Carlos III. Valladolid: Sever-Cuesta.

Ramos PÉREZ, Demetrio

1982 «El período 'fundacional' de Carmen de Río Negro y los pobladores castellanos. Vida, muerte, hambre y enfermedades», en IV Congreso Internacional de Historia de América, pp. 141-186. Buenos Aires.

Rock, James

1981 Glass Bottles: Basic Identification. Klamath National Forest, Region 5, USDA.

Rubio PÉREz, Laureano M.

1995 La burguesía maragata. Dimensión social, comercio y capital en la Corona de Castilla durante la Edad Moderna. León: Universidad de León.

2003 Los Maragatos. Origen, mitos y realidades. Zamora: Ediciones Monte Casino.

Sanguinetti de Bórmida, Amalia, Ma Ximena Senatore y Silvana Buscaglia

2005 «Patagonia en los confines de la sociedad moderna. Fronteras materiales en Floridablanca (siglo XVIII)», en Actas de la Jornadas Multidisciplinarias del Instituto Multidisciplinario de Historia y Ciencias Humanas «La Frontera. Realidades y Representaciones», pp. 69-84. Buenos Aires: Consejo Nacional de Investigaciones Científicas y Técnicas.

\section{SChÁvelzon, Daniel}

1991 Arqueología histórica de Buenos Aires. La cultura material porteña de los siglos XVIII y XIX. Buenos Aires: Ediciones Corregidor.

2001 Catálogo de cerámicas históricas de Buenos Aires (Siglos XVI-XX). Buenos Aires: Fundación para la Investigación del Arte Argentino -Telefónica - Universidad de Buenos Aires.

SenAtore, María Ximena

2007 Arqueología e Historia en la Colonia Española de Floridablanca. Patagonia, Siglo XVIII. Buenos Aires: Editorial Teseo.

Zusman, Perla

1999 «Terra australis - 'res nullius’? El avance de la frontera colonial hispánica en la Patagonia (1778-1784)». Scripta Nova 45 (34). Documento electrónico, http:// www.ub.edu/geocrit/sn-45-34.htm, con acceso el 29 de abril de 2013. 